Blocken B, Abuku M, Nore K, Briggen PM, Schellen HL, Thue JV, Roels S, Carmeliet J. 2011.

Intercomparison of wind-driven rain deposition models based on two case studies with full-scale measurements. Journal of Wind Engineering and Industrial Aerodynamics 99(4): 448-459.

\title{
Intercomparison of wind-driven rain deposition models based on two case studies with full-scale measurements
}

\author{
B. Blocken* ${ }^{(a)}$, M. Abuku ${ }^{(b)}$, K. Nore ${ }^{(\mathrm{c}, \mathrm{d})}$, P.M. Briggen ${ }^{(\mathrm{a})}$, \\ H.L. Schellen ${ }^{\text {(a) }}$, J.V. Thue ${ }^{(\mathrm{d})}$, S. Roels ${ }^{(\mathrm{e})}$, J. Carmeliet ${ }^{(\mathrm{f}, \mathrm{g})}$ \\ (a) Building Physics and Systems, Eindhoven University of Technology, P.O. box 513, 5600 MB Eindhoven, \\ the Netherlands \\ (b) Department of Architecture, School of Science and Engineering, Kinki University, 3-4-1, Kowakae, 577 - \\ 8502 Higashi-Osaka, Japan \\ (c) SINTEF Byggforsk, Hogskoleringen 7B, 7491 Trondheim, Norway \\ (d) Department of Civil and Transport Engineering, Norwegian University of Science and Technology \\ (NTNU), Hogskoleringen 7A, 7491 Trondheim, Norway \\ (e) Division of Building Physics, Department of Civil Engineering, Katholieke Universiteit Leuven, \\ Kasteelpark Arenberg 40, P.O. Box 2447, 3001 Leuven, Belgium \\ (f) Chair of Building Physics, Swiss Federal Institute of Technology ETHZ, ETH-Hönggerberg, CH-8093 \\ Zürich, Switzerland \\ (g) Laboratory for Building Technologies, Swiss Federal Laboratories for Materials Testing and Research, \\ Empa, Überlandstrasse 129, CH-8600 Dübendorf, Switzerland
}

\begin{abstract}
Three different calculation models for wind-driven rain (WDR) on buildings are compared for two case studies for which full-scale measurements are available. The models are the semi-empirical model in the ISO standard for WDR (ISO), the semi-empirical model by Straube and Burnett (SB) and the CFD model by Choi, extended by Blocken and Carmeliet. This paper builds further on two generic studies in which these models were compared based on model theory and based on their application for idealized building configurations and for constant wind and rain conditions. In the present study, the models are applied to calculate WDR on the facades of a low-rise test building and a monumental tower building for actual transient rain events. The spatial and temporal distributions of WDR at the windward facade are determined and the model results are compared with each other and with the full-scale measurements. The agreement between the CFD results and the measurements is on average $20-25 \%$, whereas the ISO and SB models show large discrepancies at many facade positions, up to a factor 2 to 5 . The identification of the reasons for the discrepancies is based on the previous generic studies and on the detailed information provided by the validated CFD simulations. The reasons include: (1) the ISO and SB model do not take into account the wind-blocking effect; (2) they do not model the variation of shelter by roof overhang as a function of the wind speed and; (3) they only provide information for a limited number of building geometries. In spite of these deficiencies, these models provide a strong basis for further development. The deficiencies can be addressed with CFD, and it is suggested that future research should focus on improving the semi-empirical models based on the detailed results of validated CFD simulations.
\end{abstract}

Keywords: wind-driven rain; driving rain; comparative evaluation; standard; airflow; facade

\section{Introduction}

The three most extensive and most frequently used calculation models for wind-driven rain (WDR) on buildings are the semi-empirical model in the ISO Standard for WDR (ISO 2009), the semi-empirical model by Straube (1998) and Straube and Burnett (2000) and the CFD model by Choi (1991, 1993, 1994a, 1994b) that was extended into the time domain by Blocken and Carmeliet (2002, 2007a). These models are referred to as ISO, SB and CFD, respectively. They can be used to assess the WDR exposure of actual building facades, for example to provide boundary conditions for numerical heat and mass transfer simulations in porous facade components. However, little is known about the accuracy of these models. To the knowledge of the authors, a comparison study of these models for actual buildings (case studies) has not yet been performed. In earlier studies, a

\footnotetext{
* Corresponding author: Bert Blocken, Building Physics and Systems, Eindhoven University of Technology, P.O.Box 513, 5600 MB Eindhoven, the Netherlands. Tel.: +31 (0)40 247 2138, Fax +31 (0)40 2438595

E-mail address: b.j.e.blocken@tue.nl
} 
comparison of the theory of the models and a comparison of model performance by application to generic, idealized buildings were provided (Blocken and Carmeliet 2010; Blocken et al. 2010). In the present paper, the models are compared by applying them to determine the spatial and temporal distribution of WDR on two actual buildings for actual, transient rain events. The first building is the rectangular test building of SINTEF Byggforsk and the Norwegian University of Science and Technology (NTNU) in Voll, Trondheim, Norway. WDR measurements on this building were reported by Nore et al. (2007) and CFD simulations were made by Abuku et al. (2009a). The second building is the tower of the St. Hubertus Hunting Lodge, a monumental building in the "De Hoge Veluwe" national park in the Netherlands. WDR measurements and CFD simulations of WDR on this building were made by Briggen et al. (2009). These two buildings are selected in this study because of: (1) the availability of high-quality experimental WDR data and of CFD simulations of WDR; (2) the previous validation of the CFD results based on the WDR measurements; and (3) the differences in building geometry (low-rise versus high-rise building).

The intention of this paper is to compare the performance of the CFD, ISO and SB models in actual situations. In such situations, many influencing parameters of WDR, including building geometrical details and variable wind and rain conditions, interact. This can result in complex WDR distributions in space and time. Obtaining a clear insight in the reasons for the differences between the models in such cases might be obscured by this complex interaction of parameters. This is the reason why a systematic approach was adopted, in which a previous paper (Blocken and Carmeliet 2010) has focused in detail on a comparison of model theory and of the model implementation of the influencing WDR parameters, to identify the intrinsic model capabilities and limitations. In a follow-up paper (Blocken et al. 2010), additional and specific model capabilities and deficiencies have been made clear by application of the three models to four idealized buildings. This knowledge is used in the present paper for the analysis of model performance in two actual case studies. Indeed, the actual purpose for which these models were developed and intended and for which they are used is to assess the WDR exposure of actual buildings under actual wind and rain conditions.

Section 2 describes the two buildings, their surroundings and the measurement set-up. In section 3.1, the three WDR models are presented with focus on the WDR coefficient. Section 3.2 summarizes the main conclusions of the two previous studies (Blocken and Carmeliet 2010, Blocken et al. 2010). The WDR models are applied to the low-rise test building in section 4 and to the high-rise tower building in section 5. Sections 6 (discussion) and 7 (conclusions) conclude the paper.

\section{Description of buildings, surroundings and measurement set-up}

\subsection{Low-rise rectangular test building, Voll, Trondheim, Norway}

The low-rise test building is located at the field station of SINTEF and NTNU. It is a rectangular building with flat roof and overall dimensions ( $\mathrm{L} \mathrm{x} \mathrm{W} \mathrm{x} \mathrm{H)} \mathrm{of} 11.3 \times 4.8 \times 4.3 \mathrm{~m}^{3}$. The building facades face the cardinal wind directions. The facade under study is oriented perfectly west and was, at the time when the measurements were taken, fully exposed to the oncoming wind. The estimated aerodynamic roughness length $\mathrm{z}_{0}$ is about 0.03 m. Fig. 1 shows the west facade, the facade dimensions and the positions and numbers of the WDR gauges (Nore et al. 2007). The length of the roof overhang is $0.34 \mathrm{~m}$. The field station is equipped with instruments to measure the relevant meteorological data. Reference wind speed $U_{10}(\mathrm{~m} / \mathrm{s})$ and wind direction $\varphi_{10}$ (degrees clockwise from north) are measured on top of a $10 \mathrm{~m}$ mast by a cup anemometer and a wind vane, respectively. A rain gauge measures horizontal rainfall intensity $\mathrm{R}_{\mathrm{h}}$. Eight wall-mounted WDR gauges with a circular collection plate made of aluminium and a catch area of $0.0314 \mathrm{~m}^{2}$ (inner diameter $=0.2 \mathrm{~m}$ ) are positioned on the west facade (Fig. 1). For more details, see Nore et al. (2007). All data were gathered on an hourly basis (as a result of 1minute or 10-minute values that were averaged over each hour). Earlier research has indicated that the use of hourly data in WDR calculations should be avoided when dealing with cumuliform rain (Blocken and Carmeliet 2007a, 2008). Therefore, in this and in previous studies using these data (Abuku et al. 2009a), rain events were chosen that are clearly of the stratiform type.

\subsection{Tower of St. Hubertus Hunting Lodge, de Hoge Veluwe, The Netherlands}

The St. Hubertus Hunting Lodge consists of a low-rise rectangular volume with wings that stretch out diagonally and with a characteristic tower in the middle of the building (Fig. 2; Briggen et al. 2009). The total building height is $34.5 \mathrm{~m}$. From the fourth floor up, the tower is rectangular with dimensions $4.8 \times 4.2 \mathrm{~m}^{2}$. There are no other buildings in the immediate vicinity, but the building is surrounded by a forest. There is an elongated clear-cut in the forest, southwest of the building, with a length of about $600 \mathrm{~m}$. For the forest, the value of $\mathrm{z}_{0}$ is estimated to be $1 \mathrm{~m}$ whereas that of the clear-cut is estimated to be $0.05 \mathrm{~m}$. The measurement set-up consisted of a meteorological mast positioned in such a way that it measured SW wind without disturbance by the building or the trees in its immediate vicinity (Briggen et al. 2009). The meteorological mast was equipped with an 
ultrasonic anemometer, providing values of $U_{10}$ and $\varphi_{10}$. $R_{h}$ was measured by a rain gauge shielded by a wind screen to reduce the wind error. The rain gauge was placed at the same location as the meteorological mast. WDR gauges $\left(0.2 \times 0.2 \mathrm{~m}^{2}\right.$ catch area, made of sheet glass according to the WDR gauge design guidelines by Blocken and Carmeliet (2006a)) were installed at the tower facades (Fig. 2a). Most gauges were positioned on the SW facade, because SW is the prevailing wind direction at this location, especially during rain events. All data were gathered on a 1-minute basis and were afterwards averaged over 10-minute intervals. More information can be found in (Briggen et al. 2009).

\section{Wind-driven rain models}

\subsection{Model equations}

The input meteorological data for the models consists of hourly or 10 -minute values of $U_{10}, \varphi_{10}$ and $R_{h}$. These hourly or 10-minute intervals are referred to as time steps. For the purpose of comparison, we represent each model based on the same equation (Eq. (1)), which allows calculating the WDR intensity $\mathrm{R}_{\mathrm{wdr}}$ for each time step:

$\mathrm{R}_{\mathrm{wdr}}=\alpha \cdot \mathrm{U}_{10} \cdot \mathrm{R}_{\mathrm{h}}^{0.88} \cdot \cos \theta$

where $\alpha$ is the WDR coefficient and $\theta$ is the angle - in a horizontal plane - between the reference wind direction $\varphi_{10}$ and the normal to the facade. Depending on the model, different expressions for $\alpha$ have to be used (Blocken and Carmeliet, 2010). In the CFD model, $\alpha$ is given by:

$\alpha=\frac{\eta \cdot \mathrm{R}_{\mathrm{h}}^{0.12}}{\mathrm{U}_{10} \cdot \cos \theta}$

where $\eta$ is the catch ratio from the CFD simulation, which is defined as the ratio $R_{w d r} / R_{h}$. For every time step and for every position at the facade, the catch ratio $\eta$ for the specific combination of reference wind speed, wind direction and horizontal rainfall intensity $\left(\mathrm{U}_{10}, \varphi_{10}, \mathrm{R}_{\mathrm{h}}\right)$ for that time step, is extracted from pre-calculated catch ratio charts (see Blocken and Carmeliet 2002). The catch ratio $\eta$ is a linear function of $U_{10}$ for those facade positions that are not sheltered by projections such as roof overhang (Blocken and Carmeliet 2008). For such positions, $\alpha$ is independent of $U_{10}$ (see Eq. 2). Both $\eta$ and $\alpha$ are a function of $R_{h}$.

The WDR coefficient in the ISO model is:

$\alpha=\frac{2}{9} \cdot \mathrm{C}_{\mathrm{R}} \cdot \mathrm{C}_{\mathrm{T}} \cdot \mathrm{O} \cdot \mathrm{W}$

where $C_{R}$ is the roughness coefficient, $C_{T}$ the topography coefficient, $O$ the obstruction factor and $W$ the wall factor. $C_{R}$ takes into account the change of mean wind speed at the site due to the height above the ground and the upstream roughness of the terrain. It is given by:

$\mathrm{C}_{\mathrm{R}}(\mathrm{z})=\mathrm{K}_{\mathrm{R}} \ln \left(\frac{\mathrm{z}}{\mathrm{z}_{0}}\right)$ for $\mathrm{z} \mathrm{z}_{\text {min }} ; \mathrm{C}_{\mathrm{R}}(\mathrm{z})=\mathrm{C}_{\mathrm{R}}\left(\mathrm{z}_{\text {min }}\right)$ for $\mathrm{z}<\mathrm{z}_{\text {min }}$

where $\mathrm{z}$ is the height above ground, $\mathrm{K}_{\mathrm{R}}$ the terrain factor and $\mathrm{z}_{\min }$ a minimum height. Values for these parameters are provided in the ISO Standard (ISO, 2009). Four terrain categories are distinguished. For example, for terrain category $\mathrm{I}, \mathrm{z}_{0}=0.01 \mathrm{~m}, \mathrm{~K}_{\mathrm{R}}=0.17$ and $\mathrm{z}_{\min }=2 \mathrm{~m}$, and for terrain category II, $\mathrm{z}_{0}=0.05 \mathrm{~m}, \mathrm{~K}_{\mathrm{R}}=0.19$ and $\mathrm{z}_{\min }=4$ $\mathrm{m}$. The topography coefficient $\mathrm{C}_{\mathrm{T}}$ takes into account the increase of mean wind speed over isolated hills and escarpments. The obstruction factor $\mathrm{O}$ takes into account the shelter of the wall by the nearest obstacle. The wall factor $\mathrm{W}$ tries to take into account the type of wall (height, roof overhang) and the variation of WDR across the surface of the wall. Some values for $\mathrm{W}$ taken from the ISO Standard are shown in Fig. $3 \mathrm{a}-\mathrm{c} . \mathrm{C}_{\mathrm{R}}, \mathrm{C}_{\mathrm{T}}, \mathrm{O}$ and $\mathrm{W}$ are constant in time, i.e. they do not vary with varying wind and rain conditions $\left(\mathrm{U}_{10}, \varphi_{10}, \mathrm{R}_{\mathrm{h}}\right)$.

The WDR coefficient in the SB model is:

$\alpha=\operatorname{DRF} \cdot \operatorname{RAF} \cdot\left(\frac{\mathrm{z}}{10}\right)^{\beta} \cdot \mathrm{R}_{\mathrm{h}}^{0.12}$

where DRF is the driving rain function, RAF the rain admittance factor, $\mathrm{z}$ the height above ground and $\beta$ the 
power-law exponent of the mean wind-speed profile corresponding to the terrain roughness of the building site. RAF values have been published by Straube (1998) and Straube and Burnett (2000), but - to the best knowledge of the authors - only for three types of buildings as illustrated in Figs. 3d-f. The RAF is constant in time; it does not vary with $U_{10}, \varphi_{10}$ and $R_{h}$. The DRF on the other hand, does vary in time, given that it is a function of $R_{h}$. The DRF is calculated as the inverse of the terminal velocity of water droplet fall $\mathrm{V}_{\mathrm{t}}$, given by the equation by Dingle and Lee (1972):

$V_{t}(d)=-0.166033+4.91844 d-0.888016 d^{2}+0.054888 d^{3} \leq 9.20 m / s$

where $d$ is the raindrop diameter. Concerning the choice of d, Straube and Burnett (2000) suggest the median diameter from the raindrop spectrum by Best (1950):

$\overline{\mathrm{d}}=1.105 \mathrm{R}_{\mathrm{h}}{ }^{0.232}$

For each model, the WDR sum $\left(\mathrm{S}_{\mathrm{wdr}}\right.$ in $\mathrm{mm}$ or $\left.\mathrm{L} / \mathrm{m}^{2}\right)$ for each time step is obtained by multiplying $\mathrm{R}_{\mathrm{wdr}}$ with the duration of the time step $(\Delta t)$. The accumulated (total) WDR at the end of the rain event, $S_{w d r, t o t}$, is given by:

$\mathrm{S}_{\mathrm{wdr}, \text { tot }}=\sum\left(\mathrm{R}_{\mathrm{wdr}} \cdot \Delta \mathrm{t}\right)$

where the summation extends over all time steps in the rain event.

\subsection{Main conclusions on model performance from previous studies}

The main conclusions from the previous comparative studies (Blocken and Carmeliet, 2010; Blocken et al., 2010) are summarized below in support of the analysis of model performance in this paper. The conclusions concern the ISO and SB model, when contrasted with the CFD model, which was shown to provide accurate results in previous validation studies (e.g. Blocken and Carmeliet 2002, 2006b, 2007b; Tang and Davidson 2004; Abuku et al. 2009a; Briggen et al. 2009).

1. The ISO and SB model only provide information (factors $W$ and RAF) for a few building types;

2. The ISO model does not take into account the variation of $\alpha$ along the width of the facade (see Fig. 3a-c);

3. Instead of providing a single value for the RAF, the SB model provides a minimum and maximum limit (see Fig. 3d-f). For some facade positions, these values bound a wide range, which limits the predictive capability of this model;

4. In the SB model, the RAF values at the top edge and vertical edge of the facade are (much) too large. Note that the factors W and RAF have exactly the same definition (Blocken and Carmeliet 2010), but that the differences between these factors for similar buildings and building positions can go up to a factor 5 (!).

5. In the $\mathrm{SB}$ model, for low $\mathrm{R}_{\mathrm{h}}$, the dependency of the $\mathrm{DRF}$ on $\mathrm{R}_{\mathrm{h}}$ is too strong;

6. The wind-blocking effect (Blocken and Carmeliet 2006b) is not reproduced by the ISO and the SB model. The wind-blocking effect refers to the decrease of upstream streamwise wind speed, and therefore also of the WDR intensity, due to the presence of the building. The reason is that the building acts as an obstruction (blockage) to the wind flow. This effect increases with the overall building dimensions. A measure for the relevant overall building dimensions is the building scaling length (BSL):

$\mathrm{BSL}=\left(\mathrm{B}_{\mathrm{L}} \mathrm{B}_{\mathrm{S}}{ }^{2}\right)^{\frac{1}{3}}$

where $\mathrm{B}_{\mathrm{L}}$ is the larger and $\mathrm{B}_{\mathrm{S}}$ is the smaller dimension of the windward facade. The BSL was defined by Wilson (1989) for estimating the dimensions of flow recirculation regions on building roofs. Blocken et al. (2010) have related the wind-blocking effect to the BSL (see Eq. (9)). For the buildings investigated it can be stated that the higher the BSL, the larger the wind-blocking effect. And the larger the wind-blocking effect, the lower the WDR exposure of the facade.

7. The increase of $\alpha$ with increasing $R_{h}$ is reproduced by the CFD model. The ISO model does not predict this dependency, while the SB shows the opposite trend (decrease with increasing $\mathrm{R}_{\mathrm{h}}$ ).

\section{Model application for the low-rise rectangular test building}

\subsection{CFD model}


The CFD model by Choi (1991, 1993, 1994a, 1994b) with the time extension by Blocken and Carmeliet (2002, 2007a) was used. 3D steady RANS simulations with the realizable k- $\varepsilon$ model (Shih et al. 1995) and with non-equilibrium wall functions (Kim and Choudhury 1995) were performed with the commercial CFD code Fluent 6.2 by Abuku et al. (2009a). The simulations were conducted following the CFD best practice guidelines by Franke et al. (2007) and Tominaga et al. (2008a) and the recommendations by Blocken et al. (2007a, 2007b) for CFD simulation of equilibrium neutral atmospheric boundary layer flow with this code. The computational grid with 1.6 million tetrahedral cells was based on grid-sensitivity analysis. The raindrop trajectories, specific catch ratio and catch ratio were all calculated with author-written program codes (see Blocken and Carmeliet 2006b). The raindrop-size distribution by Best (1950) was adopted. The simulations were made with aerodynamic roughness length $z_{0}=0.03 \mathrm{~m}$, for $U_{10}=1,2,3,4,5,6,8$ and $10 \mathrm{~m} / \mathrm{s}$, for $\theta=0,22.5,45$ and $67.5^{\circ}$ and for $\mathrm{R}_{\mathrm{h}}=0.1,0.5,1,2,3,4,5,6,8,10,12,15,20,25$ and $30 \mathrm{~mm} / \mathrm{h}$. The catch ratio $(\eta)$ and WDR coefficient $(\alpha)\left(\right.$ Eq. 2) were calculated at every position at the west facade (resolution $0.05 \times 0.05 \mathrm{~m}^{2}$ ) for the different combinations of $U_{10}, \theta$ and $R_{h}$. These values for $\alpha$ were used in Eq. (1), together with the meteorological data of the rain event, to determine the WDR intensity at different facade positions. The WDR intensities were converted to the accumulated WDR $S_{\mathrm{wdr}, \text { tot }}$ by Eq. (8). The results are presented in section 4.4.

\subsection{ISO model}

The ISO model was applied to calculate WDR at the positions of the WDR gauges (Fig. 1); this required determining the factors in Eq. (3). In this model, $C_{R}$ is only specified for $z_{0}=0.01,0.05,0.3$ and $1 \mathrm{~m}$ (ISO 2009). To obtain results for $\mathrm{z}_{0}=0.03 \mathrm{~m}$ in the present study, we calculated the ISO WDR coefficient as the average of the WDR coefficients for $\mathrm{z}_{0}=0.01 \mathrm{~m}$ and $\mathrm{z}_{0}=0.05 \mathrm{~m} . \mathrm{C}_{\mathrm{T}}$ and $\mathrm{O}$ are equal to one. The ISO model does not provide wall factors for the present building configuration, which is a one-storey building with flat roof and roof overhang. Therefore, for all positions except W1, W5 and W6, we adopted the wall factors from the "two-storey building with flat roof" (Fig. 3a). For W1, W5 and W6, which are located immediately below the roof overhang, the value from Fig. $3 \mathrm{c}$ was taken as: $\mathrm{W}=0.3$. The wall factors at the positions of the WDR gauges are summarized in Table 1. Inserting all coefficients and factors in Eq. (3) yields the WDR coefficient $\alpha$, to be used in Eq. (1). Note that $\alpha$ by the ISO model is independent of $U_{10}$ and $R_{h}$ and also independent of the position along the width of the facade.

\subsection{Model by Straube and Burnett}

Applying the SB model requires determining the factors in Eq. (5). The DRF is a function of $\mathrm{R}_{\mathrm{h}}$, as explained in section 3.1. The SB model does not provide RAF values for a low-rise building with flat roof and roof overhang (see Fig. 3d-f). Therefore, the RAF values were determined by combining Figs. 3d and 3f, where the latter was used for the positions immediately below the roof overhang (W1, W5, W6). Together with the height above ground, the minimum and maximum RAF values at the positions of the WDR gauges are given in Table 1. As power-law exponent, $\beta$ (=0.15) corresponding to $\mathrm{z}_{0}=0.03 \mathrm{~m}$ was used. Eq. (5) yields the WDR coefficient $\alpha$, to be used in Eq. (1). Note that $\alpha$ by the SB model is dependent on $R_{h}$, but independent of $U_{10}$.

\subsection{Comparison of temporal distribution of wind-driven rain}

Fig. 4a shows the meteorological data record of the stratiform rain event. Wind speed during rain was on average $3.5 \mathrm{~m} / \mathrm{s}$, but could go up to $10 \mathrm{~m} / \mathrm{s}$. Wind direction during rain was on average slightly oblique to the west facade $\left(\varphi_{10}=245^{\circ} ; \theta=25^{\circ}\right)$ and horizontal rainfall intensity was light: the average $\mathrm{R}_{\mathrm{h}}$ was only $0.32 \mathrm{~mm} / \mathrm{h}$ (value obtained by averaging during rain only; i.e. zero values were excluded).

Fig. $4 \mathrm{~b}$ shows the measured and calculated temporal distribution of WDR at position W7. A conservative estimate of the measurement error at the end of the rain event is $E_{\mathrm{wdr}}=0.5 \mathrm{~mm}$ (Abuku et al. 2009a). Qualitatively, the temporal distribution is well predicted by each of the models. This is logical because the product " $\mathrm{U}_{10} \mathrm{R}_{\mathrm{h}} \cos \theta$ " or " $\mathrm{U}_{10} \mathrm{R}_{\mathrm{h}}{ }^{0.88} \cos \theta$ " appears in the equations of each model (see Eqs. 1-5). Quantitatively, very large differences are observed. The CFD results and the measurement results are in very good agreement. The ISO model however provides large overestimations of about $100 \%$. The range between SBmin and SBmax is very large. Therefore the SB model does not provide useful quantitative information at this position.

As the product " $\mathrm{U}_{10} \mathrm{R}_{\mathrm{h}} \cos \theta$ " or " $\mathrm{U}_{10} \mathrm{R}_{\mathrm{h}}{ }^{0.88} \cos \theta$ " appears in the equations of each model, the differences between the models originate from differences in the WDR coefficient $\alpha$. Fig. $4 \mathrm{c}$ shows the temporal variation of $\alpha$ at position W7 (hourly values). The value of $\alpha_{\mathrm{CFD}}$ varies between 0 and about $0.07 \mathrm{~s} / \mathrm{m}$. The value of $\alpha_{\text {ISO }}$ is about $0.08 \mathrm{~s} / \mathrm{m}$ and is constant in time. $\alpha_{\mathrm{SBmin}}$ is zero, and $\alpha_{\mathrm{SBmax}}$ ranges between 0 (when $\mathrm{R}_{\mathrm{h}}=0 \mathrm{~mm} / \mathrm{h}$ ) and about $0.12 \mathrm{~s} / \mathrm{m}$. Note that $0.12 \mathrm{~s} / \mathrm{m}$ is the upper limit for $\alpha_{\mathrm{SBmax}}$. It is determined by the lower limit for $\mathrm{R}_{\mathrm{h}}$, which is $0.1 \mathrm{~mm} / \mathrm{h}$ (the resolution of the tipping bucket registration system). Because this is the lowest value of $R_{h}$ that 
can be measured, Eq. (5) can - for this building - not yield any value higher than $0.12 \mathrm{~s} / \mathrm{m}$. In reality, individual values for both $\alpha_{\mathrm{CFD}}$ and $\alpha_{\mathrm{SBmax}}$ can be higher. Fig. $4 \mathrm{c}$ shows that $\alpha_{\mathrm{CFD}}$ takes various values in the range $0-0.07$ $\mathrm{s} / \mathrm{m}$, while $\alpha_{\mathrm{SBmax}}$ appears to be either between 0.1 and $0.12 \mathrm{~s} / \mathrm{m}$, or equal to 0 . The reason for this is more clearly shown in Fig. 4d.

Fig. $4 \mathrm{~d}$ illustrates the variation of $\alpha_{\mathrm{CFD}}, \alpha_{\mathrm{SBmax}}$ and $\alpha_{\mathrm{SBmin}}$ in relation to $\mathrm{U}_{10}$ and $\mathrm{R}_{\mathrm{h}}$. The value of $\alpha_{\mathrm{CFD}}$ varies significantly with both parameters, especially for low $\mathrm{U}_{10}$ and/or low $\mathrm{R}_{\mathrm{h}}$. $\alpha_{\mathrm{SBmax}}$ on the other hand only varies at low $R_{h}$. A distinction is made in the following discussion between the dependency of $\alpha_{\mathrm{CFD}}$ on $\mathrm{U}_{10}$ and its dependency on $\mathrm{R}_{\mathrm{h}}$.

The variation of $\alpha_{C F D}$ with $U_{10}$ shows a specific pattern. Note that without roof overhang, $\alpha_{C F D}$ would not depend on $U_{10}$, because in that case, as previously mentioned, the catch ratio $\eta$ is a linear function of $U_{10}$ (see Fig. 4 in (Blocken and Carmeliet 2008)). With roof overhang however, $\alpha_{\mathrm{CFD}}$ at position W7 decreases with decreasing $\mathrm{U}_{10}$. The reason is that, as $\mathrm{U}_{10}$ decreases, the raindrop trajectories become more vertical, and then the roof overhang is more effective in sheltering this facade position from rain. The decrease of $\alpha_{C F D}$ between $U_{10}=$ 3 and $10 \mathrm{~m} / \mathrm{s}$ is limited. Between those values of wind speed, the roof overhang only prevents the small raindrops from reaching position $\mathrm{W} 7$. The fact that small drops are the first to be influenced by the roof overhang and to be kept away from the facade has been shown in earlier research (see specific catch ratio graphs in Fig. 12a-b in (Blocken and Carmeliet 2002)). Below $U_{10}=3 \mathrm{~m} / \mathrm{s}, \alpha_{\mathrm{CFD}}$ strongly decreases, because the roof overhang now also shelters position $\mathrm{W} 7$ from the larger drops. Below $\mathrm{U}_{10}=1 \mathrm{~m} / \mathrm{s}$, position $\mathrm{W} 7$ is completely sheltered from rain. This specific behaviour, in which the degree of shelter by the roof overhang varies with $U_{10}$, is not taken into account by the ISO and the SB model. Fig. $4 d$ shows that $\alpha_{S B m a x}$ only varies with $R_{h}$, and not with $\mathrm{U}_{10}$. As mentioned before, $\alpha_{\mathrm{ISO}}$ does neither vary with $\mathrm{U}_{10}$, nor with $\mathrm{R}_{\mathrm{h}}$.

Also the variation of $\alpha_{C F D}$ with $R_{h}$ is very pronounced. The decrease of $\alpha_{C F D}$ with $R_{h}$ is also present if there is no roof overhang (see Blocken et al. 2010), but it is more pronounced when a roof overhang is present. The reason is that, as mentioned before, at a given $\mathrm{U}_{10}$, smaller raindrops are the first to be kept away from the facade by the roof overhang, and that the fraction of smaller raindrops in the rain increases with decreasing $R_{h}(B e s t$ 1950). Fig. 4a illustrates which couples $\left(U_{10}, R_{h}\right)$ occur during the rain event. Especially for these low values of $\mathrm{R}_{\mathrm{h}}$, the differences between $\alpha_{\mathrm{CFD}}$ and $\alpha_{\mathrm{SBmax}}$ in Fig. $4 \mathrm{~d}$ are large. This explains the type of variation in Fig. $4 \mathrm{~b}$ and $4 \mathrm{c}$, and the reason for the large differences between the results in these figures.

\subsection{Comparison of spatial distribution of wind-driven rain}

Fig. 5 shows the comparison of measurements and calculations at the end of the rain event. It shows the ratio of accumulated WDR $\left(S_{\mathrm{wdr}, \text { tot }}\right)$ to accumulated horizontal rainfall $\left(\mathrm{S}_{\mathrm{h}, \mathrm{tot}}=20.3 \mathrm{~mm}\right)$ at the positions of the WDR gauges. A conservative error estimate for the measured ratio is $\mathrm{e}_{\mathrm{wdr}}=\mathrm{E}_{\mathrm{wdr}} / \mathrm{S}_{\mathrm{h} \text {,tot }}=0.5 \mathrm{~mm} / 20.3 \mathrm{~mm}=0.02$. The following observations are made:

1. Fig. 5a: the measured ratios increase from the bottom to the top, except for positions W5 and W6, where the shelter by the roof overhang causes a decreasing value. Also position W1 is influenced by the roof overhang, but in spite of this it still receives more WDR than W2, because WDR is swept sideways near the corner, which reduces the effective shelter (Blocken and Carmeliet 2002). The measured ratios also significantly increase from the centre of the facade (e.g. positions W7, W4) to the vertical edge (e.g. W2).

2. Fig. $5 \mathrm{~b}$ shows contours of the ratio across the entire facade, as obtained by CFD. The distribution is not symmetrical due to the slightly oblique wind direction. The maximum ratio occurs near the top of the windward (right) corner. The wetting gradients are most pronounced below the vertical edge, where the ratio increases from 0 to 0.15 due to the presence of the roof overhang. The narrow horizontal hatched region at the top of the facade indicates complete shelter from rain. At the positions of the WDR gauges, the CFD results increase from bottom to top, except for positions W1, W5 and W6. They also increase from the centre of the facade to the vertical edge, very similar to measurement results. The CFD results and the measurements are also in quite good quantitative agreement, except at positions W1, W5 and W6. The discrepancies at these positions are - at least partly - attributed to the fact that they are situated in the region where the wetting gradients are most pronounced. This makes the results very sensitive to the exact location at the facade. It indicates that modelling the sheltering effect provided by roof overhang, even with CFD, is difficult to achieve.

3. Fig. 5c shows the results by the ISO model. The ratio increases from bottom to top of the facade, except at the positions W1, W5 and W6. It does not increase from the centre of the facade to the vertical edge, because the ISO model does not take this variation into account (see Figs. 3a-c). The ISO model shows large overestimations at positions W4, W5, W6 and W7. Recalling section 4.4, this is attributed to (1) the fact that the ISO results - just as the SBmax results - do not take the variation of shelter with $U_{10}$ into account, and (2) the fact that the ISO model does not correctly reproduce the variation of $\alpha$ with $R_{h}$ (Fig. $4 d$ ). Given these 
limitations, and the fact that the ISO model does not consider the increase of $\alpha$ towards the vertical edge, the relatively close agreement with the measurement at position $\mathrm{W} 1$ is considered coincidental.

4. Figs. 5d-e display the results by the SB model. The min. ratios (SBmin) show a different pattern than the measurement results and the results by the other models. The max. ratios (SBmax) show the increase with height, except at the top positions W1, W5 and W6, which qualitatively corresponds to the measurements. SBmax also shows the increase from the centre of the facade to the vertical edge, except from position W8 to position W3 and from W6 to W1. The results by SBmin overestimate the measurements at positions W2, and are zero at most other positions. The maximum ratios (SBmax) are up to several times larger than the measurement results, for the same reasons as mentioned above (section 4.4 and Fig. 4d). Due to the large differences between SBmin and SBmax, the SB model does not provide useful quantitative information.

\section{Model application for the tower of St. Hubertus Hunting Lodge}

\subsection{CFD model}

3D steady RANS simulations with the realizable k- $\varepsilon$ model and with the standard wall functions by Launder and Spalding (1974) were performed with the commercial CFD code Fluent 6.3 by Briggen et al. (2009). The simulations were conducted following the CFD best practice guidelines by Franke et al. (2007) and Tominaga et al. (2008a) and the recommendations by Blocken et al. (2007a, 2007b) for CFD simulation of equilibrium neutral atmospheric boundary layer flow with this code. The computational grid with 2.1 million tetrahedral cells was based on grid-sensitivity analysis. This and other simulation details can be found in (Briggen et al., 2009). The inlet profiles are based on a logarithmic law with $\mathrm{z}_{0}=1 \mathrm{~m}$ (dense forest), but, as mentioned by Briggen et al. (2009), the local $\mathrm{z}_{0}$ of the clear-cut south-west of and around the building is much lower (short grass: $\mathrm{z}_{0} \approx 0.05$ $\mathrm{m})$. This is taken into account by specifying the equivalent sand-grain roughness height of the bottom of the computational domain according to this lower $\mathrm{z}_{0}$ value, using the relation by Blocken et al. (2007a). Simulations were only made for the SW wind direction and for the SW facade $\left(\theta=0^{\circ}\right)$. The values of $\eta$ and $\alpha($ Eq. 2$)$ were calculated at every position at this facade (resolution $0.08 \times 0.08 \mathrm{~m}^{2}$ ). All other settings and characteristics of the simulations are similar to those given in section 4.1 .

\subsection{ISO model}

Determining the value for $\mathrm{C}_{\mathrm{R}}$ requires determining the terrain category, which is not straightforward here, because of the heterogeneous character of the terrain (clear-cut surrounded by forest). Note that the updated Davenport roughness classification by Wieringa (1992) recommends $z_{0}=1 \mathrm{~m}$ for "mature" forests, while the ISO recommends $\mathrm{z}_{0}=0.3 \mathrm{~m}$ for "permanent" forests. This difference in values serves to illustrate the uncertainty involved in selecting $\mathrm{z}_{0}$ values, even if the terrain would be homogeneous. The situation is further complicated by the location of the measurements, which were made at the building site itself. As concluded from an earlier study (Blocken and Carmeliet 2010), the ISO model assumes that the meteorological data are "airfield" values, i.e. measured at an exposed site, and the value for $C_{R}$ is used to modify these airfield values in case of smoother or rougher terrain. First, the relevant terrain category for the building and the measurement set-up, for SW wind, is determined. The presence of the clear-cut will cause the development of an internal boundary layer (IBL). The height of the IBL, $\mathrm{h}_{\mathrm{IBL}}$, as a function of the distance to the roughness transition, $\mathrm{x}$, can be estimated by Eq. (10) (Jensen et al. 1984):

$\frac{\mathrm{h}_{\text {IBL }}}{\mathrm{z}_{0}^{+}}=0.3\left(\frac{\mathrm{x}}{\mathrm{z}_{0}^{+}}\right)^{0.8}$

where $\mathrm{z}_{0}{ }^{+}$is the largest of the two roughness lengths (= $1 \mathrm{~m}$ in this case). For SW wind, the upstream length of the clear-cut is about $600 \mathrm{~m}$, which yields $\mathrm{h}_{\mathrm{IBL}}=50 \mathrm{~m}$. This means that according to this equation, the building as well as the meteorological mast are completely within the IBL with $\mathrm{z}_{0}=0.05 \mathrm{~m}$. Therefore, terrain category II, corresponding to this $z_{0}$ value, is used. For this terrain category, $C_{R}$ at $10 \mathrm{~m}$ height is equal to 1 . This implies that the measurement data $\left(\mathrm{U}_{10}\right.$ and $\left.\varphi_{10}\right)$ do not need to be transformed, prior to being used for the ISO model (Blocken and Carmeliet 2010). It is recognized that Eq. (10) only provides an approximation of the height of the IBL. Given that the roughness transition is in fact 3D instead of 2D, Eq. (10) might provide estimates for $\mathrm{h}_{\mathrm{IBL}}$ that are too large.

The other two factors, $\mathrm{C}_{\mathrm{T}}$ and $\mathrm{O}$, are equal to one. The wall factors are taken from Fig. $3 \mathrm{~b}$ for a multi-storey building, although the ISO does not provide wall factors for a facade that is triangular at the top (Fig. 2a). The wall factors at the positions of the WDR gauges are given in Table 2.

\subsection{Model by Straube and Burnett}


The RAF values are taken from Fig. 3e, which seems appropriate, because $\mathrm{H}>\mathrm{W}$ applies for the tower. However, these values are strictly not applicable for positions 6 and 7, situated at the triangular part of the facade. The values at the positions of the WDR gauges and at the two additional positions (Fig. 2a) are listed in Table 2. For terrain category II, $\beta$ is 0.16 .

\subsection{Comparison of temporal distribution of wind-driven rain}

The rain event is shown in Fig. 6a. It is characterised by a series of individual showers. Wind speed is on average $1.3 \mathrm{~m} / \mathrm{s}$ and wind direction during rain is only slightly oblique to the $S W$ facade $\left(\theta \approx 0^{\circ}\right)$. $R_{h}$ ranges from 0 to $4.5 \mathrm{~mm} / \mathrm{h}$, and is on average equal to $1.2 \mathrm{~mm} / \mathrm{h}$ (zero $\mathrm{R}_{\mathrm{h}}$ values excluded). Fig. $6 \mathrm{~b}$ shows the measured and calculated temporal distribution of WDR at position 3. A conservative measurement error estimate is $\mathrm{E}_{\mathrm{wdr}}=0.2$ $\mathrm{mm}$ (Briggen et al. 2009). All models qualitatively reproduce the temporal variation. Quantitatively, CFD somewhat underestimates the measured values. ISO provides an estimate that is about four times too low, while SBmin is larger than both the measurements and the CFD results. Fig. $6 \mathrm{c}$ shows the temporal variation of $\alpha$ at the same position, and Fig. $6 \mathrm{~d}$ shows the variation of $\alpha$ with $\mathrm{U}_{10}$ and $\mathrm{R}_{\mathrm{h}}$. As opposed to the previous building, $\alpha_{\mathrm{CFD}}$ does not range from zero, but from a lower bound (non-zero value) to its maximum value. From Figure $6 \mathrm{~b}$ it is clear that position 3 is not sheltered by horizontal projections such as a roof overhang, and therefore $\alpha_{C F D}$ is not a function of $U_{10}$. It is a function of $R_{h}$, but only for low $R_{h}$ values. It is observed that the overall differences between $\alpha_{\mathrm{CFD}}$ on one hand, and $\alpha_{\mathrm{SBmax}}$ and $\alpha_{\mathrm{SBmin}}$ on the other hand, are very large. The reason for this is discussed in the next section.

\subsection{Comparison of spatial distribution of wind-driven rain}

Fig. 7 shows the comparison of measurements and calculations at the end of the rain event at the positions of the WDR gauges (1-5) and at the two additional positions near the top of the facade (6-7). A conservative estimate for the error in the measurements is $\mathrm{e}_{\mathrm{wdr}}=0.02$ (Briggen et al. 2009). The following observations are made:

1. Fig. 7a: the measured ratios increase from bottom to top, and from the middle of the facade to the sides. The value at position 5 is slightly higher than at position 3, because the wind direction is a bit lower than $225^{\circ}$. Data at position 2 are not available due to equipment malfunctioning.

2. Fig. 7b: the CFD results also show the increase with height and the increase from the middle to the sides. The agreement between CFD simulations and measurements is good, except at position 1. As mentioned by Briggen et al. (2009), this can, at least partially, be attributed to turbulent dispersion, which was not included in the CFD simulations and which can have a significant effect in regions where the raindrop trajectories are almost parallel to the facade, which is the case near position 1.

3. Fig. 7c shows that the results by the ISO model are up to four times smaller than the measurements. The same observation was made in Fig. 6b. This poor performance appears to be in contradiction to the quite good performance by the ISO model for the two idealized high-rise buildings in (Blocken et al. 2010). For these buildings, a good agreement between CFD and ISO results was found. The reason for this different performance is the wind-blocking effect (see conclusion 6 in section 3.2). This effect is present in reality but it is not reproduced by the ISO model. As mentioned in section 3.2, Blocken et al. (2010) have related the wind-blocking effect to the building scaling length (see Eq. (9)). The higher the BSL, the larger the windblocking effect. The larger the wind-blocking effect, the lower the WDR exposure of the facade. For the generic building models in (Blocken et al. 2010), the BSL for the high-rise wide building $\left(50 \times 50 \mathrm{~m}^{2}\right)$ was $50 \mathrm{~m}$, while the BSL for the high-rise tower $\left(80 \times 20 \mathrm{~m}^{2}\right)$ was $31.7 \mathrm{~m}$. For the present tower (roughly $4.8 \mathrm{x}$ $34.5 \mathrm{~m}$, when neglecting the wider bottom part), the BSL is only $9.3 \mathrm{~m}$. As a result, the actual (measured) WDR coefficients at this tower are much higher. Comparing CFD WDR coefficients has indeed shown that those for the present tower are about two to three times larger than those for the generic buildings in the previous paper. The problem is that the ISO model does not take this wind-blocking effect into account. Therefore, while it provided fairly good results for the high-rise buildings with BSL equal to $31.7 \mathrm{~m}$ and 50 $\mathrm{m}$, it provides large underestimations for the building in this study with BSL $=9.3 \mathrm{~m}$. The most probable reason is that the wall factors in the ISO model, which were based on measurements, were obtained from measurements on buildings with larger BSL values than the present tower.

4. Fig. 7d-e: SBmin and SBmax show the increase of WDR exposure with height and from the middle of the facade to the sides. As is the case for the ISO model, the SB model also does not take the wind-blocking effect into account. This could cause this model to also underestimate the WDR exposure. However, earlier research has shown that the SB model provides RAF values that are (much) too large in the vicinity of the top and side edges of high-rise buildings with rectangular facades (see conclusion 4 in section 3.2). These two effects compensate each other to some extent, but in spite of this SBmin still overestimates the 
measurements at positions 3,4 and 5. It also overestimates the CFD results at these positions. On the other hand, it does not overestimate the CFD values at positions 6 and 7. The reason is that these positions are in reality much more exposed, as the top of the facade is triangular (less wind-blocking) instead of rectangular. This causes a very high WDR exposure, as shown by the CFD results. The CFD value at the top is even larger than the value by SBmax. Note that strictly, the SB model does not provide wall factors for such positions.

\section{Discussion}

\subsection{Intercomparison of calculation models}

For both case studies, the agreement between measurements and CFD is quite good (on average 20-25\%), while the discrepancies are significantly larger for the ISO and SB model (up to a factor 2 to 5). Identifying the reasons for these discrepancies is not easy, because the temporal and spatial distribution of WDR on actual buildings is the result of the complex interaction of a large number of influencing parameters, including building geometrical details such as roof overhang and variable wind and rain conditions. Due to this complexity, it would not have been possible to obtain clear conclusions from the comparison of the different WDR calculation models in this paper, without prior knowledge of the capabilities and deficiencies of these models, as analysed in the two previous studies. The seven main conclusions from these studies have been summarized in section 3.2, and they have contributed to explaining the differences in results obtained with different models. In addition, the validated CFD results have been used to provide further insight in the deficiencies of the ISO and SB model by analysing the spatial and temporal distribution of the WDR coefficients.

The ISO and SB model only provide information (factors W and RAF) for a few building types. These do not include buildings with both a flat roof and a roof overhang (such as the low-rise rectangular Voll test building) and buildings with facades that deviate from the simple rectangular shape (such as the top of the monumental tower building). For some of these configurations, W and RAF can be estimated by combining several building configurations provided by the ISO and SB model. However, these choices are sometimes quite arbitrary. The high sensitivity of the results to these choices detracts from the applicability and reliability of the ISO and SB model.

The ISO model does not take into account the variation of the WDR coefficient along the width of the facade. This variation however is rather pronounced for the Voll building and very pronounced for the tower building. The SB model provides min. and max. values for RAF, resulting in min. and max. values of accumulated WDR. For some facade positions, these values cover a wide range, which limits the predictive capability of this model. This applies for most WDR gauge positions at the west facade of the Voll building and for positions 1 and 2 of the tower building.

The wind-blocking effect is not reproduced by the ISO and SB models. This means that the ISO and SB model might provide large discrepancies for buildings with a BSL that deviates from that of the buildings used for the establishment of the ISO and SB models and their parameters. Indeed, the ISO and SB model were developed based on measurements on a series of actual buildings, but it is not clear which buildings exactly. Deviations are likely for buildings with a rather uncommon shape, e.g. very slender buildings such as the tower building in this study.

An important note is made concerning the intended use of the ISO and SB models. The ISO model strictly only guides the calculation of the average annual amount of WDR and the amount of WDR in the worst spell in three years. But since it provides a quantitative measure, it seems logical to also apply it to determine WDR amounts or intensities for any spell within a year. Note that this is done implicitly within the ISO procedure to determine the annual and spell indices. The ISO model has been used in this way in building physics research to provide boundary conditions for heat, air and moisture (HAM) analysis. The SB model explicitly states that it is intended to provide boundary conditions for HAM analysis. Both models however contain warnings concerning their use and accuracy.

At least equally important as highlighting the deficiencies of these models, is pointing to their value and importance. Both the ISO and SB model were developed based on WDR measurements only. The development of such extensive semi-empirical models based on measurements only was undoubtedly a very difficult task, and these efforts are very praiseworthy. The models provide a strong basis for further development and improvement. Based on their comparison with more detailed information from CFD simulations, as done in this paper and its predecessors, these semi-empirical models can be further improved. In particular, future work needs to focus on exploring the limits of the applicability of the semi-empirical models. The following three important improvements are suggested: (1) taking into account the wind-blocking effect by a building, e.g. by adding a factor that is based on the BSL; (2) taking into account the effect of wind speed on the shelter provided by roof overhangs, e.g. by a shelter parameter that depends on wind speed; and (3) providing wall factors for a larger number of different building configurations. 


\subsection{Status and trends of wind-driven rain research in $C W E$}

The topic of the Special Issue in which this paper is published is "Status and Trends in Computational Wind Engineering". Therefore, this subsection has been added to briefly discuss the status and trends of WDR research in CWE. First, some brief information on the historical development of computational WDR research is given, as a summary from the review by Blocken and Carmeliet (2004). Next, a short view on the corresponding status and trends in this area is provided. The focus is on the assessment of the impinging WDR intensity on building facades, because this is also the topic of this paper. The status and trends in other interesting computational WDR topics, such as WDR absorption by porous building materials and other contact and surface phenomena (e.g. Abuku et al. 2009b) and WDR shelter by roofs in sports stadia and other constructions (e.g. van Hooff et al. 2010) are not addressed.

WDR research can be performed with three main categories of methods: (1) measurements, (2) semiempirical models and (3) numerical simulation based on CFD. An extensive review on these categories, up to 2003, is provided in (Blocken and Carmeliet 2004). Measurements have always been the primary tool in WDR research. However, they are time-consuming, expensive and prone to error, and measurements for a certain building at a certain building site have very limited applicability to other buildings at other sites. Therefore, researchers started developing semi-empirical calculation models, the earliest versions of which are attributed to Hoppestad (1955) in Norway and Lacy (1965) in the UK. These models have been progressively improved and have led to the present advanced semi-empirical model by Straube (1998) and Straube and Burnett (2000) and to the advanced semi-empirical model in the ISO Standard for WDR (ISO 2009). In the 70-ies, these advanced semi-empirical models did not yet exist, and the shortcomings of the semi-empirical models at that time, together with the complexity of WDR on buildings, drove researchers to explore the interaction between WDR and buildings by numerical simulation. Already in 1974, Sandberg (1974) calculated the movements of raindrops around a building model based on a flow pattern obtained by wind tunnel modeling. The first actual CFD effort was made by Souster (1979), who studied raindrop trajectories based on computed flow patterns around 2D buildings. However, it were the pioneering efforts by Choi (1991, 1993, 1994a, 1994b) that initiated the adoption of CFD as a tool for WDR research by the Wind Engineering and Building Physics communities. Further developments included the extension of Choi's method into the time domain (Blocken and Carmeliet 2002, 2007a) and a series of validation studies, either based on wind tunnel experiments (Hangan 1999) or on full-scale measurements (van Mook 2002, Blocken and Carmeliet 2002, 2006b, 2007, Tang and Davidson 2004, Abuku et al. 2009a, Briggen et al. 2009). The topic of the present paper marks a recent trend, in which validated CFD simulations are used to evaluate semi-empirical models, which in turn will allow these models to be improved based on the more detailed CFD results. Without going into too much detail, a few (expected) trends in WDR research in CWE are mentioned.

Up to now, most CFD simulations of WDR have been performed with steady RANS models and for isolated buildings. Two exceptions are the studies by Karagiozis et al. (1997) and Blocken et al. (2009), in which steady RANS models were applied for a two-building configuration. Given the general deficiencies of steady RANS modelling to accurately reproduce the separated wind flow beyond the windward building edges and in the building wake (Murakami 1993, Tominaga et al. 2008b), Large-Eddy Simulation (LES) or hybrid Unsteady RANS (URANS)/LES will need to be explored. This will also allow a more straightforward and accurate representation of the turbulent dispersion of raindrops. Most CFD WDR simulations up to now have been conducted based on Lagrangian particle tracking for the raindrops. As the combination of this approach with LES might lead to a very large computational cost, LES combined with an Eulerian approach for WDR should be explored to strongly decrease the computational expense. In this "Eulerian-Eulerian" approach, the rain phase, just like the air phase, is treated as a continuum. Information on Eulerian-Eulerian modeling can be found in (Shirolkar et al. 1996, Loth 2000, Zhang and Chen 2007). Note that at the time of the revision of this paper, a first RANS study employing Eulerian-Eulerian modelling of WDR has been published in this journal (Huang and Li 2010), in which this approach is successfully validated using the experimental data for the low-rise VLIET building by Blocken and Carmeliet (2005).

\section{Conclusions}

Three calculation models for wind-driven rain (WDR) deposition on building facades have been compared for two case studies, for which full-scale measurements are available. The three models are the ISO Standard model (ISO), the Straube and Burnett model (SB) and the CFD model by Choi, extended by Blocken and Carmeliet (CFD). The two buildings are the low-rise Voll test building and the monumental tower of the St. Hubertus Hunting Lodge. The intention of this paper was to compare the performance of the models in assessing the exposure of actual buildings to actual wind and rain conditions, because this is the reason why these models were developed and are applied. 
The spatial and temporal distributions of WDR at the windward facade have been determined and the model results have been compared with each other and with the full-scale measurements. The agreement between the CFD results and the measurements is quite good for both buildings (on average 20-25\%), apart from the regions just below the roof overhang of the Voll building and the bottom part of the monumental tower. The latter is attributed to the fact that the turbulent dispersion of the raindrops was not modelled. The ISO and SB model however show large discrepancies with the measurements at most facade positions, up to a factor 2 to 5 . The identification of the reasons for these discrepancies was supported by the conclusions from two previous generic comparison studies.

The main reasons for the discrepancies by the ISO and SB model in the two case studies are the following:

- The ISO and SB model only provide information on wall factors and rain admittance factors for a few building types. It is not clear what factors should be used for the particular geometry of the Voll building and for the triangular-shaped upper part of the tower, which is the part that receives most WDR.

- The ISO model does not take into account the variation of the WDR exposure along the width of the facade

- The ISO and SB model do not take into account the wind-blocking effect, which is especially important for the slender tower building.

- The ISO and SB model do not take into account the variation of shelter by roof overhang with wind speed.

- The rain admittance factors by the SB model at the top edge and vertical facade edges are too large.

While this paper has highlighted a number of important deficiencies of the ISO and SB models, it should be noted that these models are nevertheless very valuable. These developments have provided a very strong basis for further development and improvement of semi-empirical models based on validated CFD simulations. It is hoped that the present study can contribute to these further improvements.

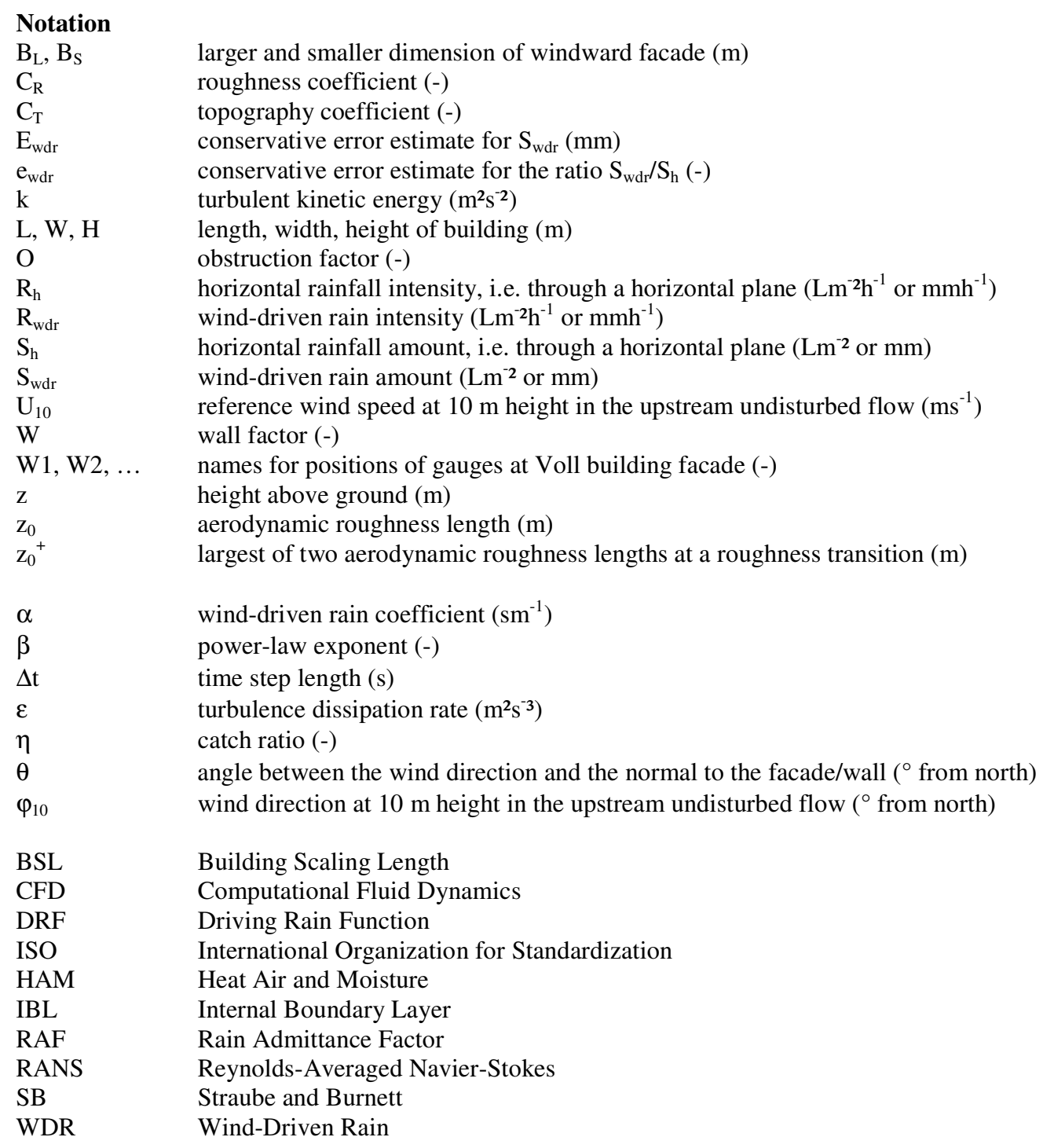




\section{References}

Abuku M., Blocken B., Nore K., Thue J.V., Carmeliet J., Roels S. 2009a. On the validity of numerical wind-driven rain simulation on a rectangular low-rise building under various oblique winds. Building and Environment 44, $621-632$.

Abuku M., Janssen H, Poesen J, Roels S. 2009b. Impact, absorption and evaporation of raindrops on building facades. Building and Environment 44(1), 113-124.

Best, A.C., 1950. The size distribution of raindrops, Quarterly Journal of the Royal Meteorological Society 76, 1636.

Blocken, B., Carmeliet, J. 2002. Spatial and temporal distribution of driving rain on a low-rise building, Wind and Structures 5(5), 441-462.

Blocken, B., Carmeliet, J. 2004. A review of wind-driven rain research in building science. Journal of Wind Engineering and Industrial Aerodynamics 92(13), 1079-1130.

Blocken B, Carmeliet J. 2005. High-resolution wind-driven rain measurements on a low-rise building experimental data for model development and model validation. Journal of Wind Engineering and Industrial Aerodynamics 93(12), 905-928

Blocken, B., Carmeliet, J. 2006a. On the accuracy of wind-driven rain measurements on buildings, Building and Environment 41(12), 1798-1810.

Blocken, B., Carmeliet, J. 2006b. The influence of the wind-blocking effect by a building on its wind-driven rain exposure, Journal of Wind Engineering and Industrial Aerodynamics 94(2), 101-127.

Blocken, B., Carmeliet, J. 2007a. On the errors associated with the use of hourly data in wind-driven rain calculations on building facades. Atmospheric Environment 41(11), 2335-2343.

Blocken, B., Carmeliet, J. 2007b. Validation of CFD simulations of wind-driven rain on a low-rise building facade. Building and Environment 42(7), 2530-2548.

Blocken, B., Stathopoulos, T., Carmeliet, J. 2007a. CFD simulation of the atmospheric boundary layer: wall function problems, Atmospheric Environment 41(2), 238-252.

Blocken B, Carmeliet J, Stathopoulos T. 2007b. CFD evaluation of the wind speed conditions in passages between buildings - effect of wall-function roughness modifications on the atmospheric boundary layer flow. Journal of Wind Engineering and Industrial Aerodynamics 95(9-11): 941-962.

Blocken B., Carmeliet J., 2008. Guidelines for the required time resolution of meteorological input data for wind-driven rain calculations on buildings. Journal of Wind Engineering and Industrial Aerodynamics 96(5), 621-639.

Blocken B., Dezsö G, van Beeck J, Carmeliet J., 2009. The mutual influence of two buildings on their winddriven rain exposure and comments on the obstruction factor. Journal of Wind Engineering and Industrial Aerodynamics 97(5-6): 180-196.

Blocken B., Carmeliet J., 2010. Overview of three state-of-the-art wind-driven rain assessment models and comparison based on model theory. Building and Environment 45(3), 691-703.

Blocken, B., Deszö, G., van Beeck, J., Carmeliet, J. 2010. Comparison of calculation methods for wind-driven rain deposition on building facades. Atmospheric Environment 44(14), 1714-1725.

Briggen, P.M., Blocken, B., Schellen, H.L. 2009. Wind-driven rain on the facade of a monumental tower: numerical simulation, full-scale validation and sensitivity analysis, Building and Environment 44(8), 16751690.

Choi E.C.C., 1991. Numerical simulation of wind-driven-rain falling onto a 2-D building. Proceedings of Asia Pacific Conference on Computational Mechanics, Hong Kong, 1721-1728.

Choi, E.C.C., 1993. Simulation of wind-driven rain around a building. Journal of Wind Engineering and Industrial Aerodynamics 46\&47, 721-729.

Choi, E.C.C. 1994a. Determination of wind-driven rain intensity on building faces. Journal of Wind Engineering and Industrial Aerodynamics 51, 55-69.

Choi, E.C.C. 1994b. Parameters affecting the intensity of wind-driven rain on the front face of a building. Journal of Wind Engineering and Industrial Aerodynamics 53: 1-17.

Dingle AN, Lee Y. 1972. Terminal fall speeds of raindrops. Journal of Applied Meteorology 11: 877-879.

Franke, J., Hellsten, A., Schlünzen, H., Carissimo, B. 2007. Best practice guideline for the CFD simulation of flows in the urban environment. COST 732: Quality Assurance and Improvement of Microscale Meteorological Models.

Hangan, H. 1999. Wind-driven rain studies, A C-FD-E approach. Journal of Wind Engineering and Industrial Aerodynamics 81: 323-331.

Hoppestad, S. 1955. Slagregn i Norge (in Norwegian), Norwegian Building Research Institute, rapport Nr. 13, Oslo. 
Huang SH, Li QS. 2010. Numerical simulations of wind-driven rain on building envelopes based on Eulerian multiphase model. Journal of Wind Engineering and Industrial Aerodynamics 98(12): 843-857.

ISO, 2009. Hygrothermal performance of buildings - Calculation and presentation of climatic data - Part 3: Calculation of a driving rain index for vertical surfaces from hourly wind and rain data. ISO 15927-3:2009.

Jensen, N.O., Petersen, E.L., Troen, I. 1984. Extrapolation of mean wind statistics with special regard to wind energy applications. WMO World Climate Applications Programme TD-No. 15, 85 p.

Karagiozis A, Hadjisophocleous G, Cao S. 1997. Wind-driven rain distributions on two buildings. Journal of Wind Engineering and Industrial Aerodynamics 67-68: 559-572.

Kim S-E, Choudhury D. 1995. A near-wall treatment using wall functions sensitized to pressure gradient. In: Separated and complex flows, ASME FED, vol. 217.

Lacy, R.E. 1965. Driving-rain maps and the onslaught of rain on buildings, RILEM/CIB Symposium on Moisture Problems in Buildings, Rain Penetration, vol. 3, paper 3-4, Helsinki, August 16-19, 1965.

Launder BE, Spalding DB. 1974. The numerical computation of turbulent flows. Computer Methods in Applied Mechanics and Engineering 3:269-89.

Loth, E. 2000. Numerical approaches for motion of dispersed particles, droplets, and bubbles. Progress in Energy and Combustion Science 26:161-223.

Murakami, S., 1993. Comparison of various turbulence models applied to a bluff body. Journal of Wind Engineering and Industrial Aerodynamics 46 \& 47, 21-36.

Nore, K., Blocken, B., Jelle, B.P., Thue, J.V. and Carmeliet, J. 2007. A dataset of wind-driven rain measurements on a low-rise test building in Norway. Building and Environment 42(5): 2150-2165.

Richards, P.J., Hoxey, R.P., 1993. Appropriate boundary conditions for computational wind engineering models using the k- $\varepsilon$ turbulence model. Journal of Wind Engineering and Industrial Aerodynamics 46\&47: 145-153.

Sandberg P.I., 1974. Driving rain distribution over an infinitely long high building: computerized calculations, Second International CIB/RILEM Symposium on Moisture Problems in Buildings. Rotterdam, The Netherlands, 10-12 September 1974, Paper 1-1-2.

Shih, T.H., Liou, W.W., Shabbir, A., Zhu, J. 1995. A new k- $\varepsilon$ eddy-viscosity model for high Reynolds number turbulent flows - model development and validation, Computers \& Fluids 24(3), 227-238.

Shirolkar JS, Coimbra CFM, McQuay MQ. 1996. Fundamental aspects of modeling turbulent particle dispersion in dilute flows. Progress in Energy and Combustion Science 22(4):363-99.

Souster, C. 1979. A theoretical approach to predicting snow loads and driving rain deposition on buildings, Ph.D. Thesis, University of Sheffield, UK, 1979.

Straube, J.F. 1998. Moisture control and enclosure wall systems, Ph.D. thesis, Civil Engineering, University of Waterloo, Ontario, Canada, 318 p.

Straube, J.F., Burnett, E.F.P. 2000. Simplified prediction of driving rain on buildings, Proc. of the International Building Physics Conf., Eindhoven, The Netherlands, 18-21 September 2000, 375-382.

Tang W., Davidson C.I., 2004. Erosion of limestone building surfaces caused by wind-driven rain. 2. Numerical modelling. Atmospheric Environment 38(33), 5601-5609.

Tominaga, Y., Mochida, A., Yoshie, R., Kataoka, H., Nozu, T., Yoshikawa, M., Shirasawa, T. 2008a. AIJ guidelines for practical applications of CFD to pedestrian wind environment around buildings. Journal of Wind Engineering and Industrial Aerodynamics 96(10-11), 1749-1761.

Tominaga, Y., Mochida, A., Murakami, S., Sawaki, S., 2008b. Comparison of various revised k- $\varepsilon$ models and LES applied to flow around a high-rise building model with 1:1:2 shape placed within the surface boundary layer. Journal of Wind Engineering and Industrial Aerodynamics 96(4): 389-411.

Van Hooff, T., Blocken, B., van Harten, M. 2010. 3D CFD simulations of wind flow and wind-driven rain shelter in sports stadia: influence of stadium geometry. Building and Environment 46(1): 22-37.

Van Mook, F.J.R. 2002. Driving rain on building envelopes, Ph.D. Thesis. Building Physics Group (FAGO), Eindhoven University of Technology, Eindhoven University Press, Eindhoven, The Netherlands, 2002, 198 p.

Wieringa, J., 1992. Updating the Davenport roughness classification. Journal of Wind Engineering and Industrial Aerodynamics 41-44: 357-368.

Wilson D.J., 1989. Airflow around buildings, ASHRAE Handbook of Fundamentals, pp. 14.1-14.18.

Zhang Z, Chen Q. 2007. Comparison of the Eulerian and Lagrangian methods for predicting particle transport in enclosed spaces. Atmospheric Environment 41(25): 5236-5248. 


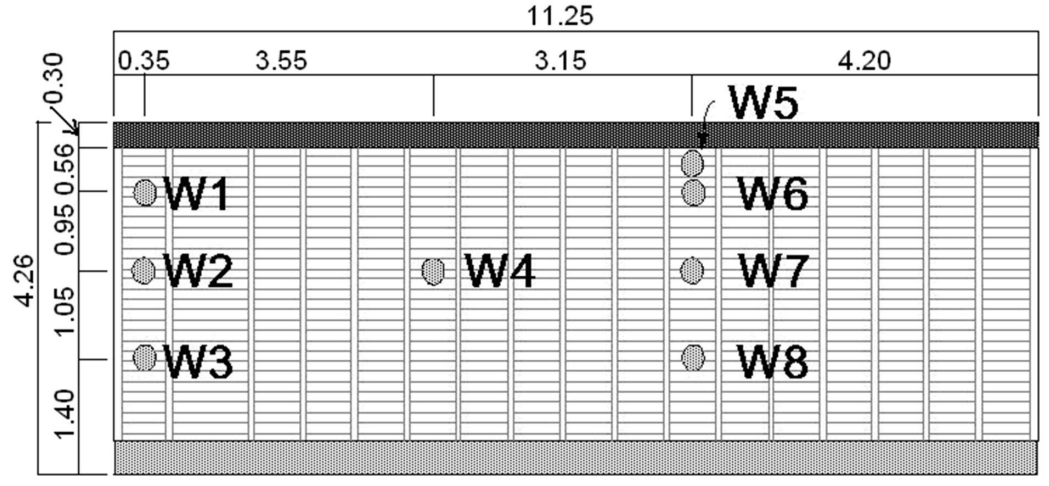

Fig. 1. West facade of the rectangular Voll test building and the positions and numbers (W1 to W8) of the winddriven rain gauges at the facade. Dimensions are in $\mathrm{m}$. Roof overhang length is $0.34 \mathrm{~m}$.

(a)

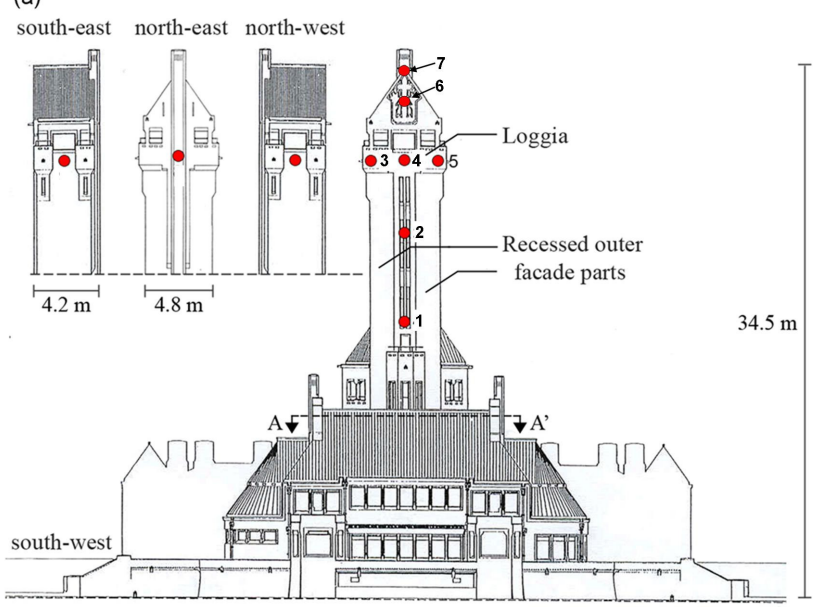

(b)

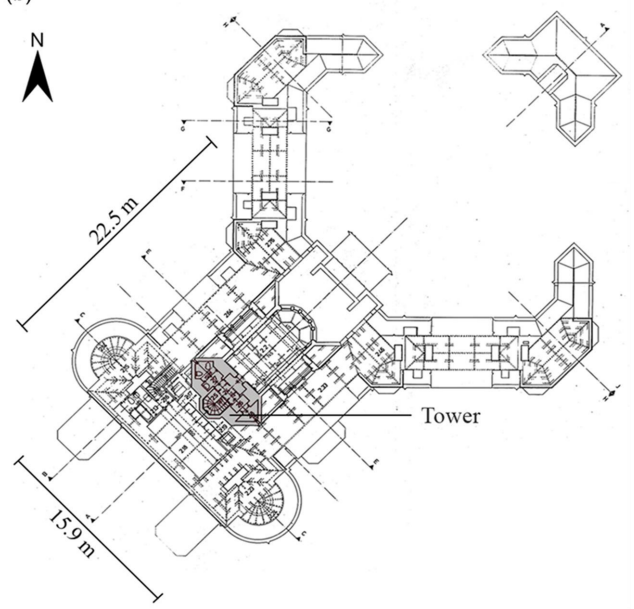

Fig. 2. (a) South-west facade of Hunting Lodge St. Hubertus and the positions and numbers of the wind-driven rain gauges (1-5) and of two additional positions without gauges (6-7) at the SW facade; (b) cross section A-A' (indicated in Fig. 2a) of the building. Dimensions are in $\mathrm{m}$. 
(a)

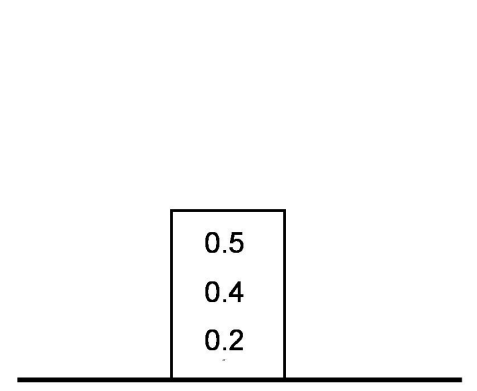

Two-storey building with flat roof (pitch $<20^{\circ}$ )

(d)

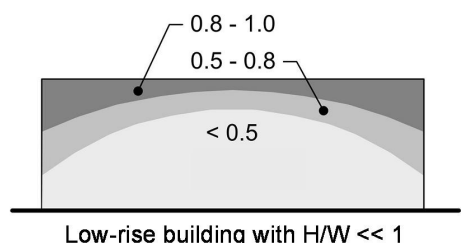

(b)

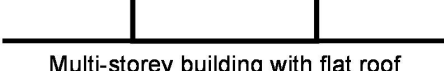

Multi-storey building with flat roof (pitch $<20^{\circ}$ )

(e)

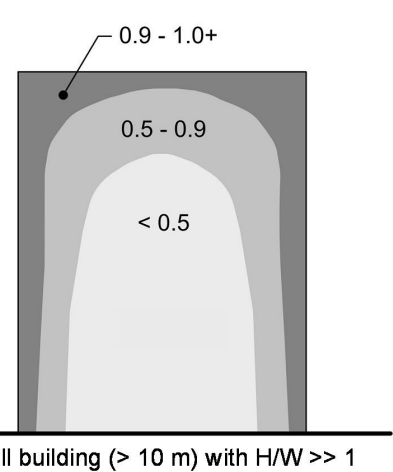

(c)

0.5 for top $2.5 \mathrm{~m}$

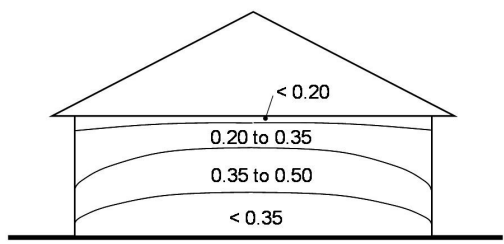

Fig. 3. (a-c) ISO Standard wall factors (W) on the windward facade of a two-storey building with flat roof, a multi-storey building with flat roof and a two-storey eaves building (modified from ISO (2009)); (d-f) Contours of Straube and Burnett's rain admittance factor (RAF) on the windward facade of a wide low-rise building with flat roof, a high-rise building and a low-rise building with pitched roof (Straube 1998, Straube and Burnett 2000). 
(a)

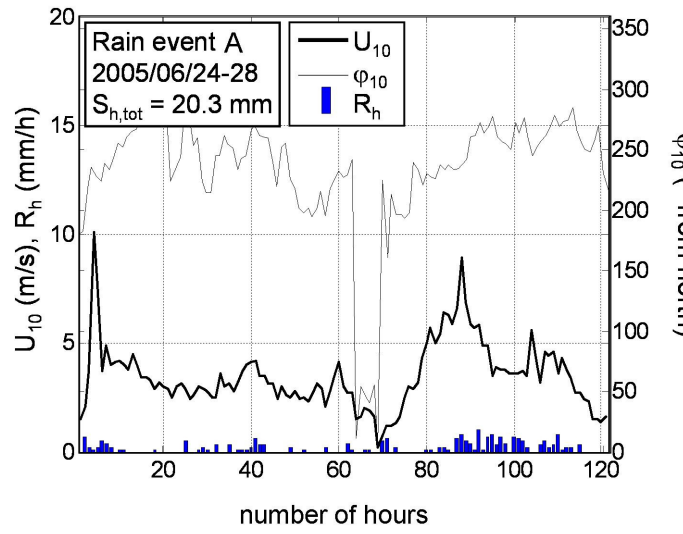

(c)

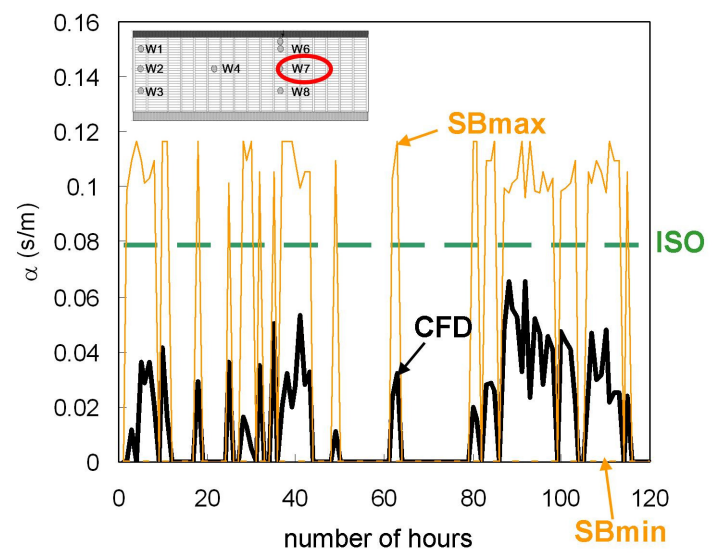

(b)

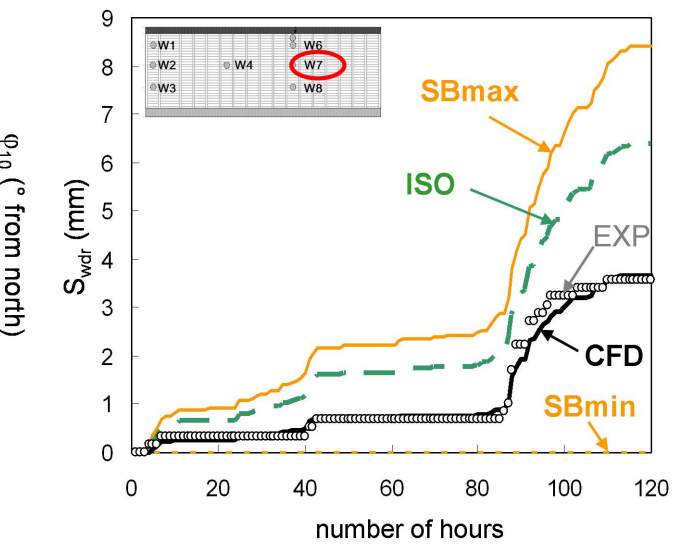

(d)

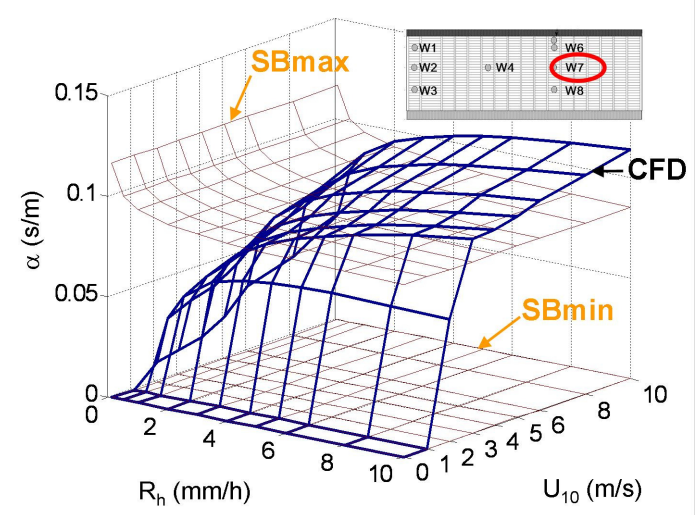

Fig. 4. Results for the Voll building and rain event A: (a) Meteorological data record (hourly data); (b) Temporal distribution of cumulative wind-driven rain at position W7 from experiments and CFD, ISO and SB models; (c) Temporal distribution of wind-driven rain coefficient $\alpha$ at position W7 for CFD, ISO and SB models; (d) Variation of $\alpha$ at position $\mathrm{W} 7$ with $\mathrm{U}_{10}$ and $\mathrm{R}_{\mathrm{h}}$ according to CFD and SB model. 
(a) Experiments

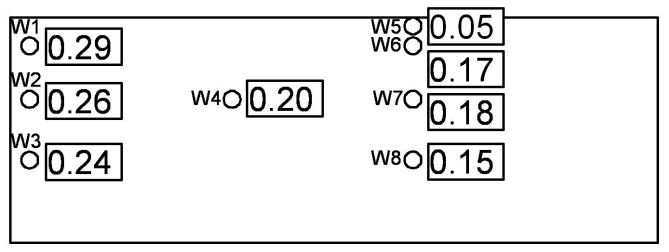

(b) CFD

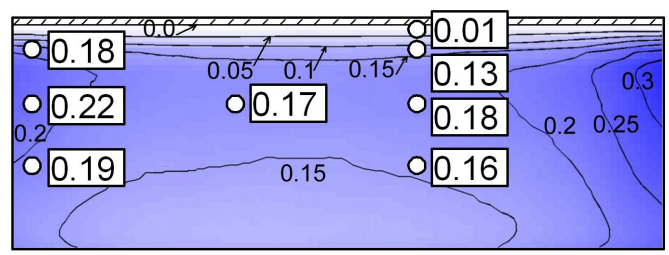

(d) Straube and Burnett - MIN (SBmin)

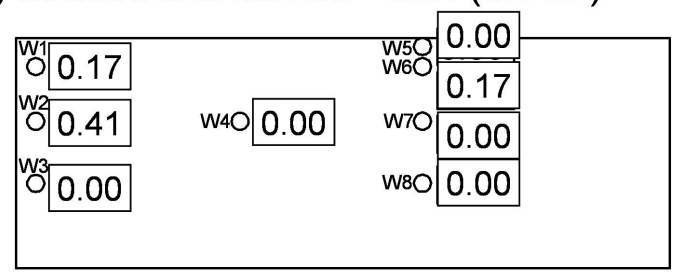

(c) ISO Standard (ISO)

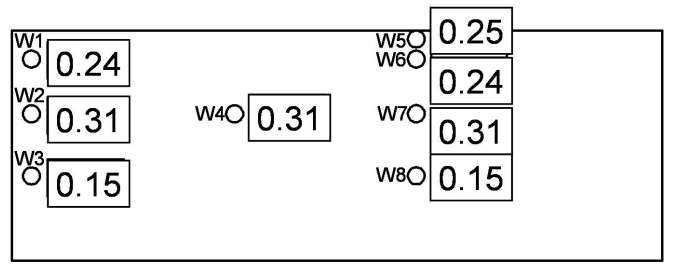

(e) Straube and Burnett - MAX (SBmax)

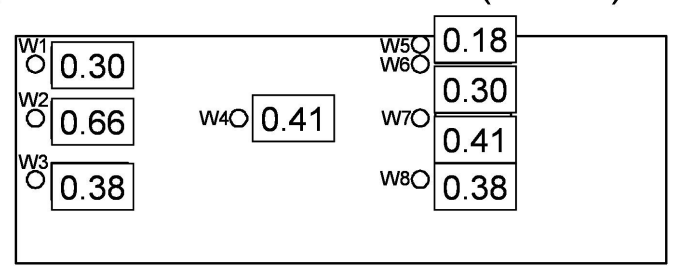

Fig. 5. Experimental and calculation results at end of rain event A: spatial distribution across the windward facade of the ratio of accumulated wind-driven rain to accumulated horizontal rainfall. 
(a)

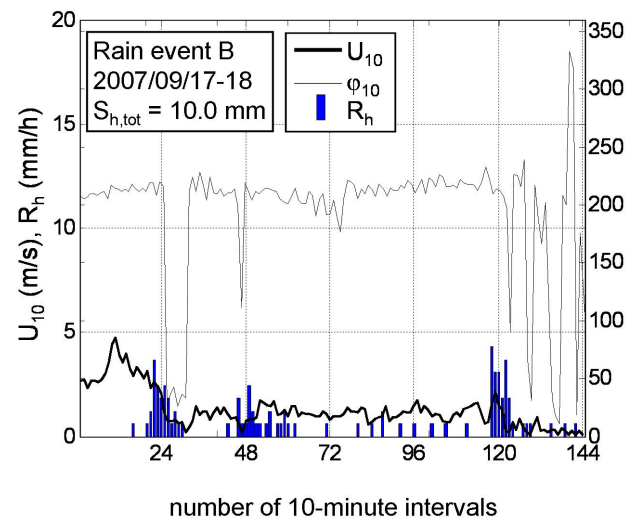

(c)

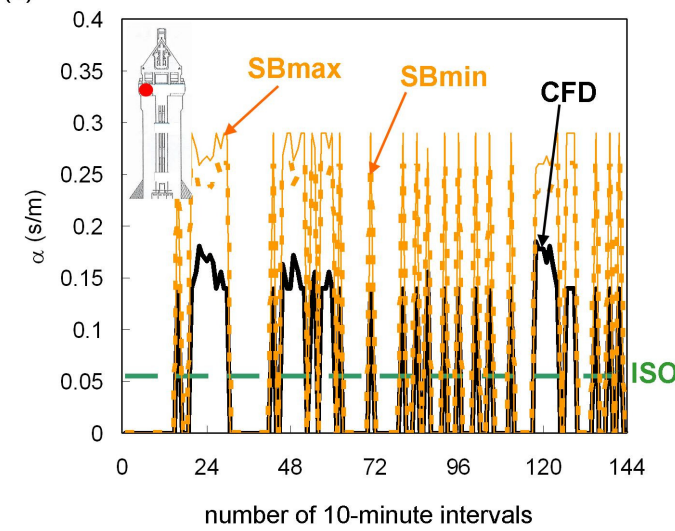

(b)

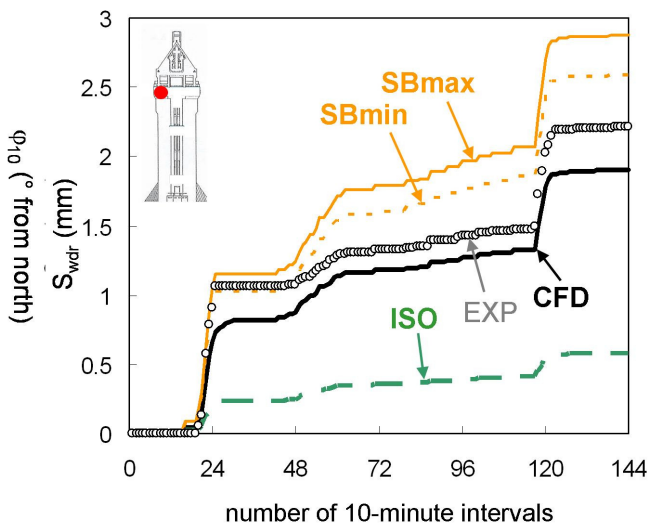

(d)

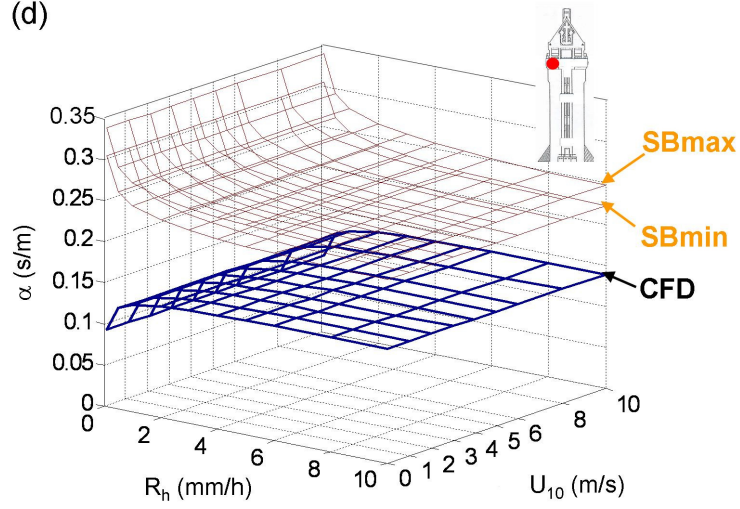

Fig. 6. Results for tower building and rain event B: (a) Meteorological data record (10-minute data); (b) Temporal distribution of cumulative wind-driven rain at position 3 from experiments and CFD, ISO and SB models; (c) Temporal distribution of wind-driven rain coefficient $\alpha$ at position 3 for CFD, ISO and SB models; (d) Variation of $\alpha$ at position 3 with $U_{10}$ and $R_{h}$ according to CFD and SB model.

(a) Experiments

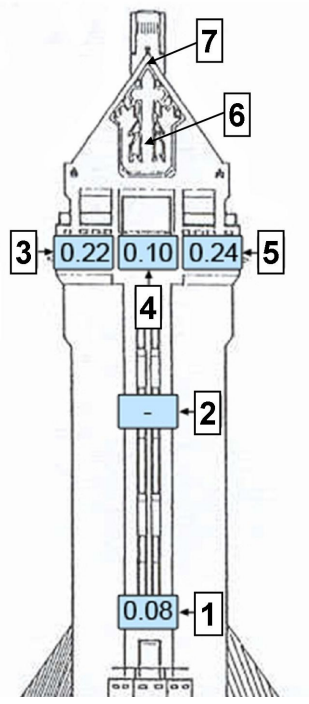

(b) CFD
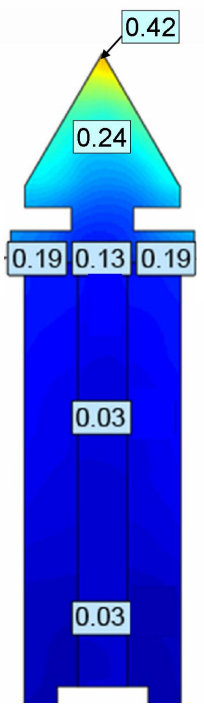

(c) ISO

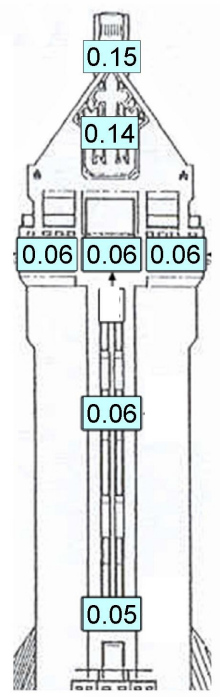

(d) SBmin

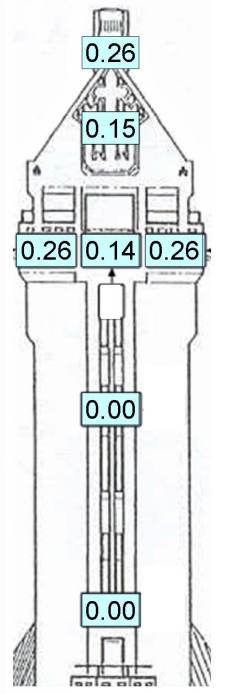

(e) SBmax

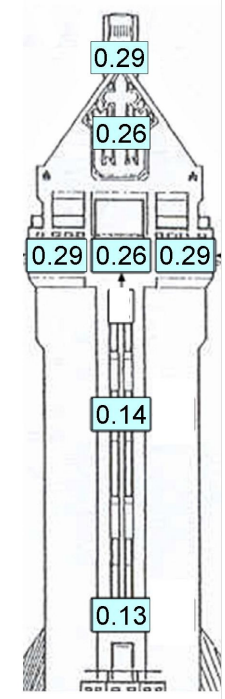

Fig. 7. Experimental and calculation results at end of rain event B: spatial distribution across the windward facade of the ratio of accumulated wind-driven rain to accumulated horizontal rainfall. 
Table 1. Data for positions at the west facade of the Voll building: height $\mathrm{z}$, wall factor $\mathrm{W}$ and maximum and minimum rain admittance factor RAF, as obtained from Fig. 3.

\begin{tabular}{lcccccccc}
\hline & $\begin{array}{l}\text { W1 } \\
(\mathbf{m m})\end{array}$ & $\begin{array}{c}\text { W2 } \\
(\mathbf{m m})\end{array}$ & $\begin{array}{c}\text { W3 } \\
(\mathbf{m m})\end{array}$ & $\begin{array}{c}\text { W4 } \\
(\mathbf{m m})\end{array}$ & $\begin{array}{c}\text { W5 } \\
(\mathbf{m m})\end{array}$ & $\begin{array}{c}\text { W6 } \\
(\mathbf{m m})\end{array}$ & $\begin{array}{c}\text { W7 } \\
(\mathbf{m m})\end{array}$ & $\begin{array}{c}\text { W8 } \\
(\mathbf{m m})\end{array}$ \\
\hline $\mathrm{Z}(\mathrm{m})$ & 3.4 & 2.45 & 1.4 & 2.45 & 3.75 & 3.4 & 2.45 & 1.4 \\
$\mathrm{~W}$ & 0.3 & 0.4 & 0.2 & 0.4 & 0.3 & 0.3 & 0.4 & 0.2 \\
RAF_min & 0.2 & 0.5 & 0 & 0 & 0 & 0.2 & 0 & 0 \\
RAF_max & 0.35 & 0.8 & 0.5 & 0.5 & 0.2 & 0.35 & 0.5 & 0.5 \\
\hline
\end{tabular}

Table 2. Data for positions at the south-west facade of the tower St. Hubertus: height $\mathrm{z}$, wall factor W and maximum and minimum rain admittance factor RAF, as obtained from Fig. 3.

\begin{tabular}{lccccccc}
\hline & $\begin{array}{c}\text { SW1 } \\
(\mathbf{m m})\end{array}$ & $\begin{array}{c}\text { SW2 } \\
(\mathbf{m m})\end{array}$ & $\begin{array}{c}\text { SW3 } \\
(\mathbf{m m})\end{array}$ & $\begin{array}{c}\text { SW4 } \\
(\mathbf{m m})\end{array}$ & $\begin{array}{c}\text { SW5 } \\
(\mathbf{m m})\end{array}$ & $\begin{array}{c}\text { SW6 } \\
(\mathbf{m m})\end{array}$ & $\begin{array}{c}\text { SW7 } \\
(\mathbf{m m})\end{array}$ \\
\hline $\mathrm{z}(\mathrm{m})$ & 18.5 & 24.5 & 29.5 & 29.5 & 29.5 & 32.2 & 34.5 \\
W & 0.2 & 0.2 & 0.2 & 0.2 & 0.2 & 0.5 & 0.5 \\
RAF_min & 0 & 0 & 0.8 & 0.5 & 0.8 & 0.5 & 0.8 \\
RAF_max & 0.5 & 0.5 & 1 & 0.8 & 1 & 0.8 & 1 \\
\hline
\end{tabular}

